\title{
Retraction Note: Drought environment monitoring and national health exercise data monitoring based on embedded image processing
}

\author{
Yuanyuan Feng ${ }^{1,2} \cdot$ Guangming Qing ${ }^{1}$
}

Published online: 15 November 2021

(c) Saudi Society for Geosciences 2021

Retraction Note to: Arabian Journal of Geosciences (2021) 14: 1015 https://doi.org/10.1007/s12517-021-07274-1

The Editor-in-Chief and the Publisher have retracted this article because the content of this article is nonsensical. The peer review process was not carried out in accordance with the Publisher's peer review policy. The authors have not responded to correspondence regarding this retraction.

The original article can be found online at https://doi.org/10.1007/ s12517-021-07274-1.

Guangming Qing

fyy19840801@163.com

1 Chengdu Sport University, Chengdu 610041, Sichuan, China

2 Sichuan Agricultural University, Ya' an 625014, Sichuan, China 